\title{
A Business Case for Flexible Housing: The Feasibility of Implementing Flexibility Measures in the Housing
} Market

\author{
Robert Pierre Geraedts and Joost Ruiterkamp \\ Delft University of Technology, Faculty of Architecture, Department Management in the Built Environment, Delft 2600GA, The \\ Netherlands
}

\begin{abstract}
Adaptive construction is already for decades on the agenda of the construction sector. The adaptive capacity of a building includes all qualities that enable the building keeping its functionality during the technical life cycle, under altered conditions and needs [1]. Meanwhile, the interest in flexible building has increased significantly caused by the growing awareness of the need for sustainability. The Dutch construction sector is responsible for $35 \%$ of the national waste production. This number emerges from a sector that accounts for $5.1 \%$ of the gross domestic product [2]. This paper reports about a study that was executed in collaboration with a Dutch real estate developer [3]. The purpose was to develop a successful business case for a flexible row house concept that could show the market under what conditions flexibility measures for future adaptations can be implemented. One of the main conclusions affirms that a long-lasting collaboration between a developer and the investor could result in a feasible business case if the developer stays involved during the use phase of the dwellings. Through many additional interviews, this research was able to let the real estate market reflect about the business case of flexible row housing.
\end{abstract}

Key words: Business case, flexible, adaptable, sustainable, feasible, housing, developer.

\section{Introduction}

The choice for the research subject of a flexible housing concept arises from three important aspects. The Dutch construction sector accounts for $35 \%$ of the national waste production in Holland. This number emerges from a sector that accounts for $5.1 \%$ of the gross domestic product [2]. This inefficiency motivates for research to make the sector more efficient; flexibility can provide a solution.

A changing demand and market trends result in buildings that are already obsolete before they are taken into operation [4]. A flexible dwelling can be adjusted to the changing market and user demand in the

Corresponding author: Robert Pierre Geraedts, associate professor design and construction management; research fields: flexibility and adaptability of buildings, the flexibility of the design and construction process, the reuse and transformation of vacant buildings into new functions. E-mail: R.P.Geraedts@tudelft.nl. future. One of the trends that cause a changing demand is the aging of the population. It is predicted that $20 \%$ of the Dutch population is 75 or older in 2040 [5]. Demands will change due to this fact, but will also evaluate after the aging period is over.

\section{Problem Framing}

The building real estate developer for this research-Heijmans Vastgoed-focuses on the development of a product and completes his task when the product is finished and can be handed over to the customer [6]. Flexibility offers benefits during the use phase of the dwelling. The wish for a broader scope of Heijmans is in line with the need to utilize the advantages of flexibility during the use phase of the dwelling. The question is if this offers chances for a win-win situation for a business case with a long lasting collaboration between the developer and the investor? Basic idea is that a long lasting collaboration 
gives an extra incentive to make use of the taken flexibility measures when demands are changing in the future.

\subsection{Flexibility and the Importance of Taking into} Account the Consumer Requirements

Flexibility focuses on the easy way of making adjustments when the conditions for the building or the plot are changing. Ref. [7] defines a flexible building as a building that can be adjusted when the demand changes. In this way, a dwelling is able to answer the changing needs of the occupant what results into the extension of the lifespan of the dwelling. This leads to an increase of sustainability because the building materials will have an increase in lifespan [7].

The Durban paper "Adaptive Capacity of Buildings" forms the basis for this research. It focuses on the adaptability in three ways. A distinction is made for organization flexibility, process flexibility and product flexibility [1]. Organization flexibility is focused on the end user who will adjust its lifestyle to its living environment instead of the other way around. This will not result in a living environment that satisfies the demand of the end user, but the end user will learn how to cope with the boundary conditions that its living environment is giving.

In Fig.1, the different forms of flexibility are showed [1]. Process flexibility focuses on the flexibility of the building process, the processes during the initial phase, the design phase and the construction phase of the project.

Product flexibility is the actual degree of adaptability during the use phase of the dwelling. This research project is focused on product flexibility, the adaptability of a dwelling in the future.

The outcome of previous studies showed that the implementation of flexibility measures does not always result in the completion of a meaningful flexible project [8]. Meaningful in this case is characterized as a project that actually uses the implemented flexibility measures during the use phase. In-depth target group research is needed to be able to foresee the actual requirements of the target group for the flexible concept [9].

\subsection{Dwelling Type}

Ground floor dwellings are most feasible when they are constructed as row-dwellings. Real estate developer Heijmans has much experience with row-dwellings because this type of dwelling is commonly used in the

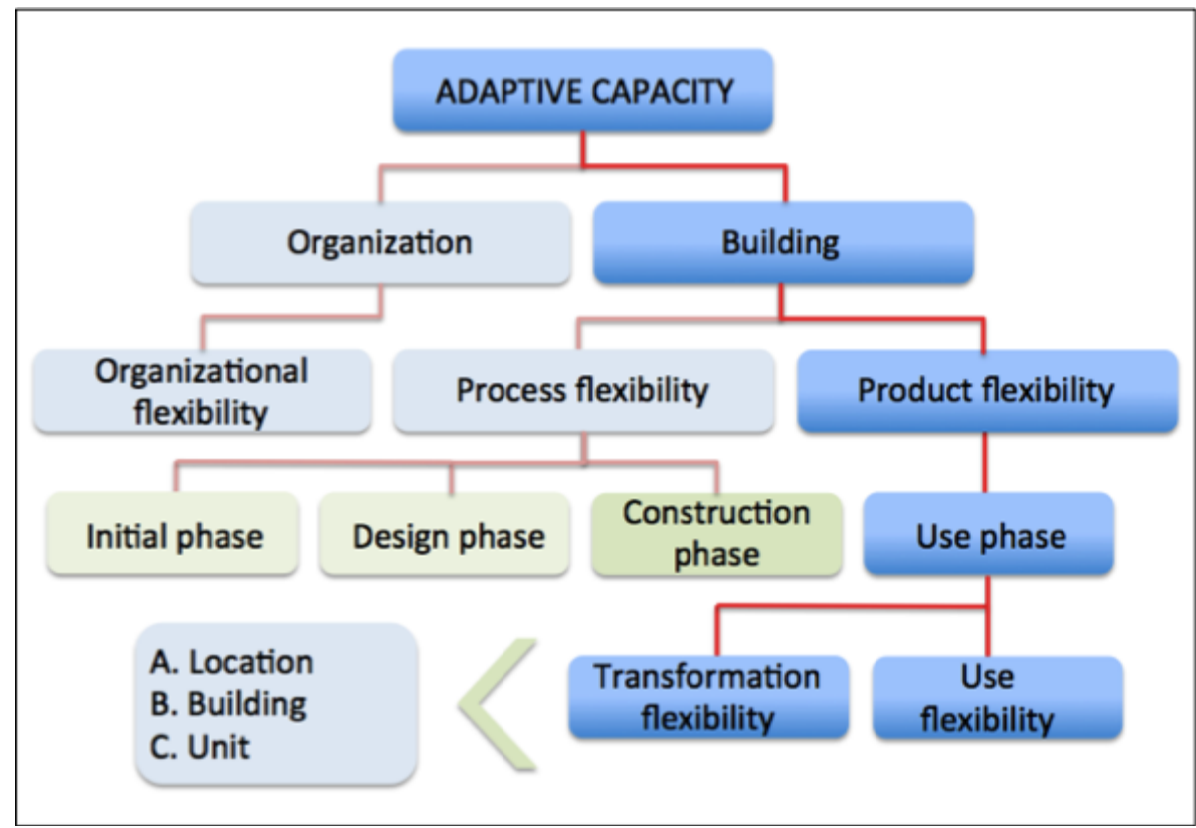

Fig. 1 Adaptive capacity, the types of flexibility related to the different life cycle phases at three different levels [1]. 
Netherlands. Row-dwellings will be the focus of this research project. The complete database from Heijmans has been used as a starting point for the right information about materialization, costs and measurements. Another focus of this research project is the rental sector. The main reason for this is the construction of a new business case for the flexible row-dwelling concept. The business case will consist of collaboration between the developer and the investor. Rental income will provide the revenues for the joining parties so that a feasible business case can be generated. Therefore this research focuses on the rental sector.

\subsection{Target Group}

The geographical focus of the research will be the western part of the Netherlands. This is caused by the expected shortage for housing in this area in the near future. Because the middle-income households of the private rental sector show a prolonged shortage, this research will focus on the target group with a middle income [10]. Also, from the target group analysis can be concluded that the age category is an important variable for the life-stage of the target group [11]. For this research, the age categories will consist of the groups 18-29 years, 30-49 years, 50-64 years and 65 years or older.

\subsection{Business Case Development}

A business case is a recommendation for policymakers to choose for a certain direction of the organization. This is supported by the analysis of advantages, costs and risks compared to realistic alternatives [12]. A business case focuses on the strategic advantages, indirect costs and organizational factors [13]. The business case in this research will consist of the following aspects [12]:

- Actor analysis;

- Organizational framework;

- Company policy integration;

- Financial framework, with a focus on a cost-benefit analysis;
- Goals and performance framework;

- Management platform.

Overall this business case can be typed as feasible when the intended return is reached with a net present value of 0 for rent prices, which are in line with the market.

\subsection{Problem Definition}

It is currently unknown under what conditions meaningful flexibility measures can be implemented in a flexible row-dwelling concept to ensure that the dwelling is adjustable for the different life-stages of the target group and whether this implementation delivers a feasible business case for a long-lasting collaboration between the developer and the investor.

The objective of this research project is to construct an innovative row-dwelling concept that shows the market under what conditions flexibility measures can be implemented in dwellings. The focus is on the financial feasibility of the concept through a life-cycle costs approach in the development of a business case.

\section{Research Questions}

The research project provides answers to the two main research questions:

- How can a new flexible row-dwelling concept be designed for the western part of the Netherlands?

- Does a long-lasting collaboration between the developer and the investor for this flexible row-dwelling concept result in a feasible business case?

The flexible row-dwelling concept is based on the existing dwelling of real estate developer Heijmans called the Heijmans Huismerk dwelling (Fig. 2).

During the design of the concept research has been carried out to the meaning of flexibility and which consumer requirements need to be taken into account. With the use of so called "practical reports", flexible measures can be distinguished which will be connected to the consumer requirements and trends for the target group by the "flexibility triangle". The flexibility 


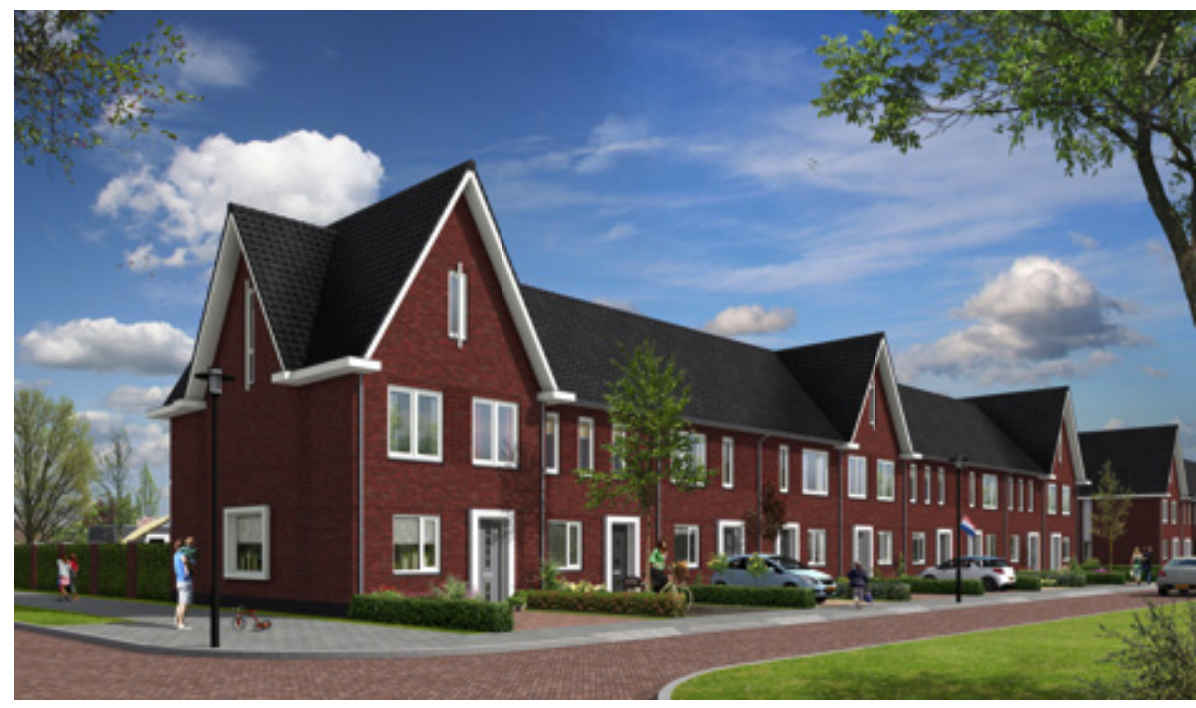

Fig. 2 Flexible row-dwelling concept is based on the existing Heijmans so-called Huismerk dwelling [17].

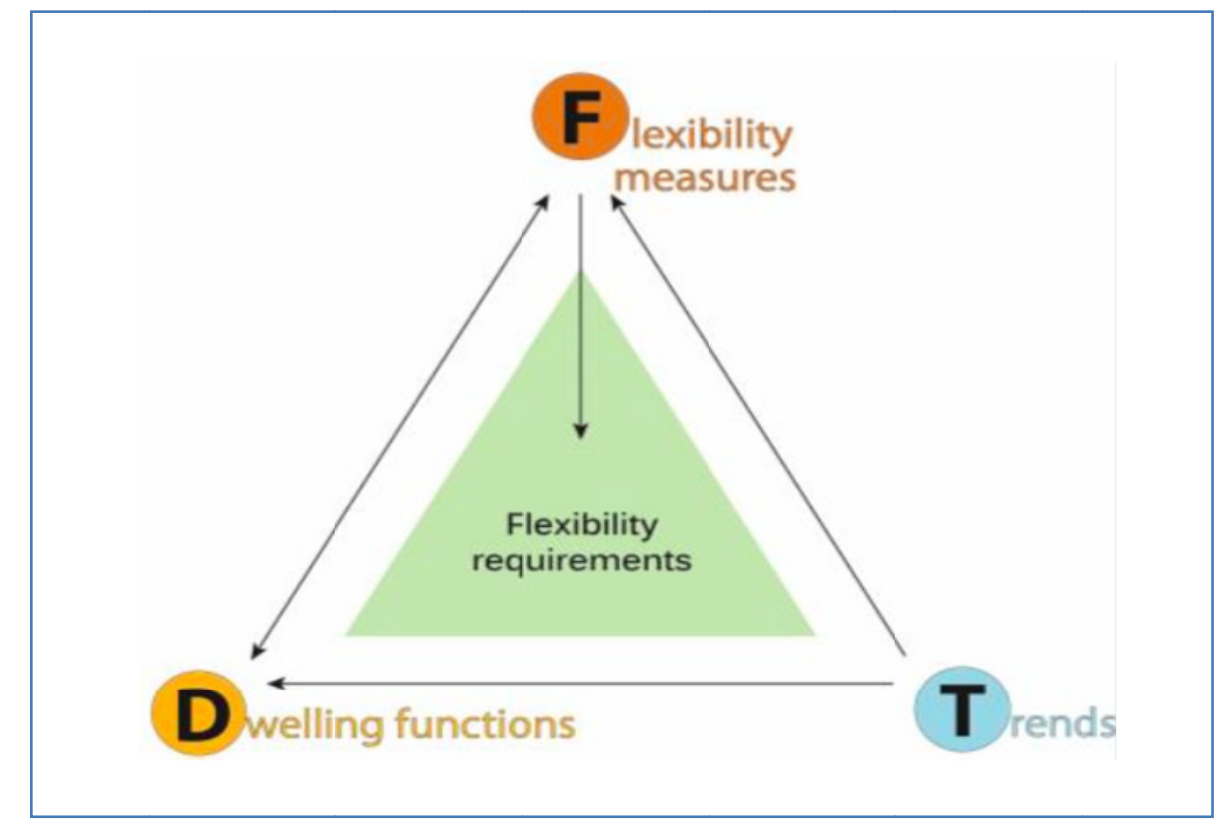

Fig. 3 The flexibility triangle; the changing demand for flexibility measures, market trends and the supply of flexibility measures [3].

triangle gives the flexibility requirements for the row-dwelling concept (Fig. 3). The different constraints for the business case are elaborated with a focus on the company policy, the actors in the business case and the financial framework. With the use of these constraints, the business case is tested for market potential in the client base of Heijmans. This resulted in meetings with different types of investors for row-dwellings in the Netherlands.

\section{Flexible Row-Dwelling Concept}

The flexible row-dwelling concept is based on the standard Heijmans Huismerk dwelling. This dwelling is transformed into a flexible row dwelling with the use of the constructed flexibility-triangle that makes a connection between dwelling functions, flexibility measures and trends. The flexibility-triangle can be found in Fig. 3. 
The total amount of dwelling functions consists of general dwelling functions that are obtained from research on activities in dwellings by the target group [14] and the flexible dwelling functions that are obtained from the adaptive capacity study [15]. This results into the following main dwelling functions for the flexible row-dwelling concept:

- Sleep function;

- Residence function;

- Eat function;

- Universal function;

- Outdoors function;

- Personal care function;

- Extension function;

- Rearrange function;

- Rejection function.

Flexibility measures can be typed as the measures to implement in a dwelling to be able to adjust the dwelling to the changing user demand. The flexibility measures are separated into spatial-functional measures and construction-technical measures [1]. Furthermore, the trend of aging is an important factor in the evolution of the housing sector. This is why trends became a third aspect in the flexibility-triangle. The development based on the flexibility requirements gives an incentive for the construction of two types of width sizes for the flexible row-dwelling concept:

- 5,400 mm, strongly based on the standard dwelling, as well width as layout;

- 7,500 mm, ideal for flexibility of rearrangements, but more expensive.

For both dwelling types, a standard pre-investment is made to ensure the future adaptability of the dwelling. This pre-investment consists of the elements of Table 1 and will cost around $€ 11,000$. See also Table 4 for a more detailed calculation. Because of this investment, at least 14 different adjustments can be made during the use phase of the dwelling. These adjustments are called adaptability options and can be found in Table 2 .

To be able to construct the flexible row-dwelling

Table 1 Summary of the implemented flexibility measures of flexibility measures per dwelling function; not presented in the table are the design implementations for the spatial requirements.

\begin{tabular}{|c|c|c|c|}
\hline Dwelling function & Implemented flexibility requirement & Dwelling function & Implemented flexibility requirement \\
\hline \multirow[t]{2}{*}{ 1. Sleep function } & Flexible walls (Bowall or Masterwall) & \multirow[t]{4}{*}{ 7. Extension function } & Extension capable foundation \\
\hline & Plinth system for wiring & & Preparation for dormer \\
\hline \multirow[t]{2}{*}{ 2. Residence function } & Flexible walls (Bowall or Masterwall) & & Demountable back facade \\
\hline & Plinth system for wiring & & Possibility for splitting facilities \\
\hline 3. Eat function & Strategic empty floor spaces & \multirow[t]{3}{*}{ 8. Rearrange function } & Possibility kitchen at first floor \\
\hline \multirow[t]{2}{*}{ 4. Universal function } & Flexible walls (Bowall or Masterwall) & & Box-in-box bathroom \\
\hline & Plinth system for wiring & & 2 Fontanels in construction floor \\
\hline \multirow[t]{5}{*}{ 5. Personal care function } & Threshold $<20 \mathrm{~mm}$ rounded & \multirow[t]{5}{*}{ 9. Rejection function } & House separating floor \\
\hline & Flexible walls (Bowall or Masterwall) & & House separating wall next to stairs \\
\hline & Accessible facilities shafts & & House separating stairs \\
\hline & Possibilities for brackets/shower chair & & Convector heating instead of floor heating \\
\hline & & & Possibility for splitting facilities \\
\hline
\end{tabular}

Table 214 different adaptability options for the flexible row-dwelling concept.

\begin{tabular}{ll}
\multicolumn{2}{c}{ Adaptability options during use phase } \\
\hline Adaptable inner walls & Bathroom for disabled \\
\hline Extension at the back side of the house & Toilet for disabled \\
Construction of a (bed)room & Bathtub \\
\hline Bathroom ground floor & Roof terrace (with extension ground floor) \\
\hline Extendable kitchen & Dormer \\
\hline Kitchen on first floor & Skylight \\
Dwelling split (ground and first floor) & Power points
\end{tabular}


concept in the proper way, various preconditions need to be taken care of. The location gives the first precondition; it needs to be suitable for the different life-stages of the target group. Secondly, the urban situation has to be suitable for the implementation of one of the width-types of the flexible row-dwelling concept. Thirdly, the municipality has to be supportive for the creation of flexible dwellings with a possibility to adjust the dwelling to future demands. Adjustability has to be found in extensions of the dwelling, rearranging of the dwelling or rejection of (part of) the dwelling.

\section{Creation of the Business Case}

The actor analysis leads to the relation between the main actors for the business case. For the flexible row-dwelling concept, the three main actors are the developer, the investor and the end-user. The developer and investor have the most influence at the business case, although it has a major impact in day-to-day life for the end-user.

\subsection{Four Scenario's for the Business Case}

The scenarios are approached from four different

Table 3 Four different scenarios for the business case.

\begin{tabular}{|c|c|}
\hline & Scenario 1: Home sweet home \\
\hline Time & Adjustment \\
\hline Year 1 & $2 \times$ power points \\
\hline Year 6 & Extra interior wall $18 \mathrm{~m} 2$ \\
\hline & Dormer for extra room \\
\hline Year 15 & Extension for extra living room space \\
\hline Year 22 & Change place interior wall (hobby) \\
\hline Year 25 & End of exploitation period \\
\hline & Scenario 3: Conscious older \\
\hline Time & Adjustment \\
\hline Year 6 & Skylight for attic \\
\hline Year 16 & Dwelling split \\
\hline & Elderly home om ground floor \\
\hline & Bathroom/toilet for disabled \\
\hline Year 20 & Wiring adjustment through plint \\
\hline Year 25 & End of exploitation period \\
\hline
\end{tabular}

angles and are applied on the two different width types. Also, they anticipate on trends and on the possible flexibility options of the dwellings. Furthermore, the fourth scenario is fully based on the life-stage approach obtained from the activities in dwellings research [14]. A short summary of the scenario's can be found in Table 3 .

\subsection{Preconditions}

The business comes up from validated aspects but still preconditions need to be drawn. The financial precondition is that the business case needs a stable economic climate to create the results that the financial framework gives.

The functional precondition is that the functional flexibility of the dwelling is limited to the flexibility measures that are taken. There will not be an endless flexibility in the dwelling due to the considerations that had to be made. Furthermore, also, the market potential has a precondition. The test for market potential remains to be called positive but changes in the market can have a big influence on the feasibility of the business case.

\begin{tabular}{ll}
\hline & \multicolumn{1}{c}{ Scenario 2: The divorce } \\
\hline Time & Adjustment \\
\hline Year 5 & Dwelling split \\
& Normal single dwelling on ground floor \\
\hline Year 10 & Roof terace \\
\hline year 15 & Dormer and bathtub \\
Year 19 & 3x power points \\
\hline Year 25 & End of exploitation period
\end{tabular}

Scenario 4: Life cycle according to Meesters

\begin{tabular}{ll}
\hline Time & Adjustment \\
\hline Year 2 & Skylight; Extra interior wall $18 \mathrm{~m} 2$ \\
\hline Year 10 & Kitchen extension ground floor \\
Year 14 & Extension extra living room \\
& Roof terrace \\
Year 20 & $2 \times$ power points \\
Year 25 & End of exploitation period
\end{tabular}




\subsection{Real Estate Developer Policy}

The flexible row-dwelling concept has a relation with the current company policy of Heijmans. This relation can be found in the way the flexible row-dwelling concept broadens the scope of Heijmans. Broadening the scope is done by the long-lasting collaboration between the investor and Heijmans where Heijmans is responsible for the maintenance and the adjustments to the dwelling.

\subsection{Management Platform and Goals}

The management platform gives the steps to take at the start of executing the business case. These steps are similar to the steps that have to be taken for regular development projects; determine land positions, specific target-group analysis, attracting investors. Also, the business case comes with some risks. The main risk aspect can be found in the long-lasting collaboration with another commercial party, in this situation, you are dependent on the other company and dependent on their choices.

The five main goals of the business case are: future adaptability, counteract to the static character of dwellings, efficient use of building materials, financial feasibility and the extension of the total lifetime of the dwelling.

\subsection{Extra Costs for Future Adaptability}

Together with two financial experts, one from an external company [18] and one from real estate developer Heijmans [19], costs calculations have been made of the necessary flexibility measures for future adaptations (see Table 4).

\subsection{Financial Framework}

The calculated cash flow models are based on the life cycle cost approach. With these models, the different

Table 4 Detailed costs calculations of necessary flexibility measures for future adaptations (reference date November 2014).

\begin{tabular}{lc}
\hline Flexibility Requirement & Extra costs/dwelling $€$ \\
\hline Plinth system for wiring & $2.071,-$ \\
\hline Flexible walls (Bowall or Masterwall) & $2.189,-$ \\
\hline Strategic empty floor spaces & $726,-$ \\
Accessible facilities shafts & $413,-$ \\
Demountable back facade & $1.000,-$ \\
Extension capable foundation & $1.477,-$ \\
Possibility for splitting facilities (facade) & $354,-$ \\
\hline Preparation for dormer & $472,-$ \\
House separating floor & $922,-$ \\
\hline House separating wall next to stairs & $141,-$ \\
House separating stairs & $0,-$ \\
Removable bathroom (box in box) & $835,-$ \\
Extra facade & $1.812,-$ \\
2 Fontanels in construction floor & $90,-$ \\
Threshold <20mm rounded & $94,-$ \\
Protective plastic strips screed floor & $35,-$ \\
Convector heating instead of floor heating & $0,-$ \\
Entrance door 1000mm & $177,-$ \\
\hline
\end{tabular}




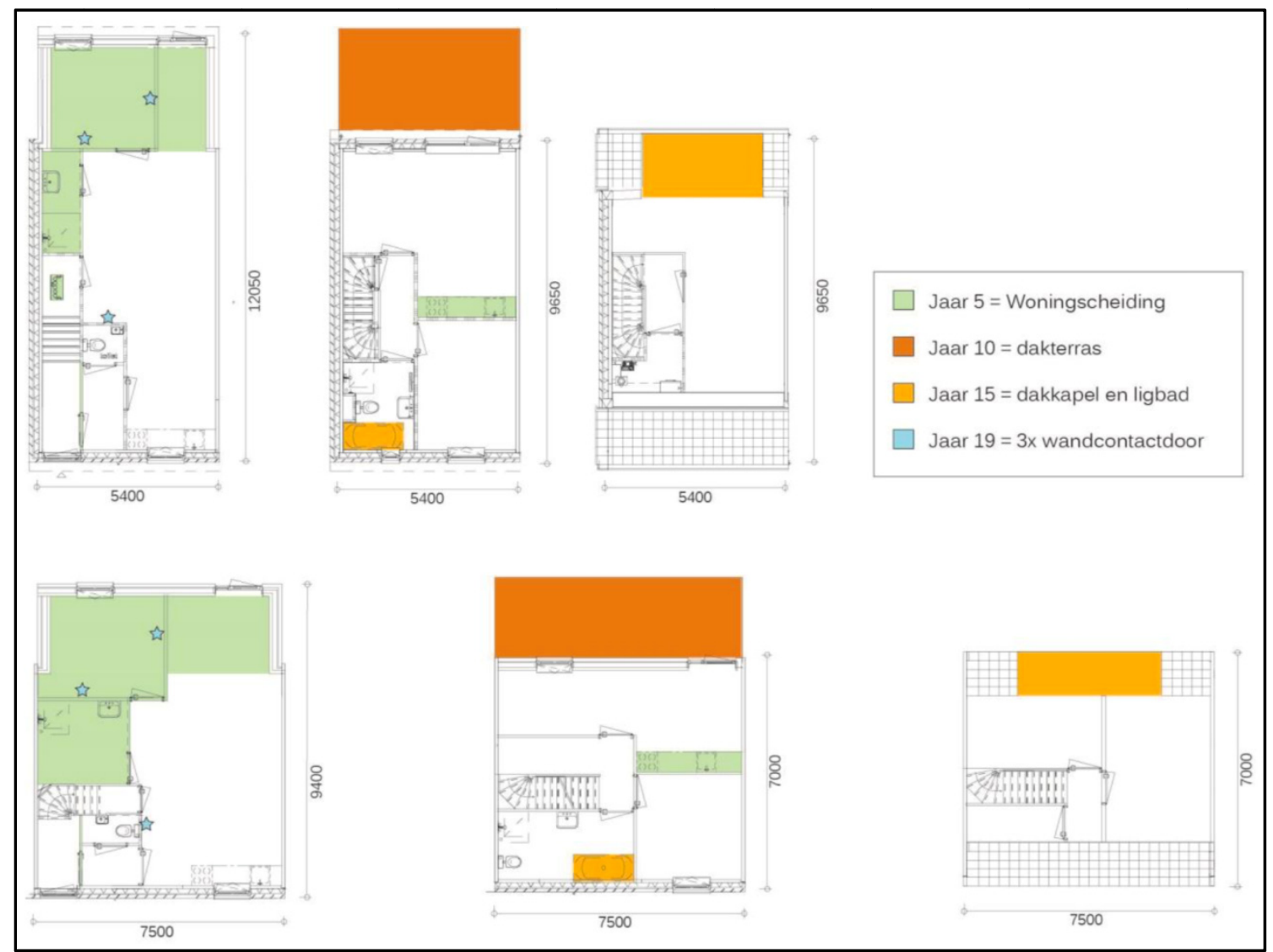

Fig. 4 Basic Scenario 2: divorce after 5 years and separation into two dwellings, in Year 10 adding a roof terrace, in Year 15 adding dormer and bathtub, in Year 9 three new wall sockets.

scenarios have been calculated so that a comparison can be made between the two flexible width types of the concept and the standard Heijmans Huismerk dwelling (see Fig. 4). It can be concluded that it would more feasible to invest in the flexible row-dwelling concept when the adjustments are big and complex. Investments in these kind of possible adjustments are less expensive during the first construction phase than afterwards during the use phase.

\subsection{Viability of the Business Case}

The evaluation of the concept with several experts in practice shows that the concept is structural and architectural viable. Only the structural-architectural choices have an influence on the financial viability. The financial framework is consulted with the market to test the market prices and the market potential. The test showed that different parties have different ways to approach an aspect like maintenance costs and therefore it can be concluded that the feasibility is also influenced by the assumptions that have been made by different sources. Overall it can be concluded that all the four scenarios attain the needed financial feasibility. The uncertainty still follows from the actual implementation of the flexibility options and the degree that the flexibility measures are used in the future.

\subsection{Influence on Financial Feasibility}

Some external factors can have influence on the financial feasibility but cannot only be expressed in euros. One of these factors is the Green Performance of Real Estate score (GPR-Gebouw) [16], a score that tells something about the sustainability of a building in five sustainability themes; future value is one of them together with energy, environment, health and use quality.

Because of the increase of the future value, an aspect 
like the GPR-Gebouw score will increase and that will have a positive effect on the market value of the dwelling. Also, for example in Amsterdam, there is a possibility for a subsidy for adaptable houses.

\section{Conclusions}

The main research questions of this research were: how can a new flexible row-dwelling concept be designed for the western part of the Netherlands, and does a long-lasting collaboration between the developer and the investor for this flexible row-dwelling concept result in a feasible business case?

\subsection{Design of a Flexible Row-Dwelling Concept}

The design of the flexible row-dwelling concept has been executed with the use of the flexibility triangle (Fig. 3). The demand for a flexible dwelling will originate from the general demand and the flexibility demand for dwellings. Together this will result in the needed supply, the needed dwelling functions. The link in the flexibility triangle between dwelling functions, flexible measurements and market trends result in the flexibility requirements. These requirements function as a guideline during the development of the flexible row-dwelling concept.

\subsection{Feasibility of the Business Case}

It can be concluded that a long-lasting collaboration between the developer and the investor will result in a feasible business case. An important aspect is the degree and complexity of the future adjustments. For example, it is financially more attractive to implement an extension at the ground floor for the flexible row-dwelling concept compared to the regular Heijmans Huismerk dwelling. The implementation of, for example, a skylight will not result in a financially more attractive situation for the flexible row-dwelling concept. When the situation is approached from real estate developer Heijmans' point of view, the involvement in the use-phase of the dwellings will result in an increase of income for that specific project.
This increase follows from the extra income of maintenance and the future adjustments.

\subsection{Goals of the Flexible Row-Dwelling Concept}

When the goals of the flexible row-dwelling concept are reached and when the dwelling actually gets a longer meaningful total lifespan, this will result in an increase of income for Heijmans for that specific project but does not have to result in a total benefit for Heijmans. The construction of dwellings is one of the main businesses of Heijmans. When the lifespan of houses will be increased, this could result in a decrease of the number of houses that have to be built and that will have a negative effect on the main business of developer Heijmans.

\subsection{The Opinion of the Market}

By many additional interviews, this research was able to let the real estate market reflect about the business case of flexible row housing. ${ }^{1}$ All approached market parties defined the concept as customer-oriented, the business case successful and were highly interested in the concept.

Changes start with initiatives and people that can carry the load. This research was able to let the real estate market reflect on flexible row-dwellings. All market parties characterize the concept as customer-oriented. It can be concluded that market parties are interested in the concept. They see the added value of flexibility, only they are not sure of the way to implement it. The flexible row-dwelling concept does not have to be the only suitable answer for this.

\section{References}

[1] Geraedts, R., Remøy, H., Hermans, M., and Van Rijn, E. 2014. "Adaptive Capacity of Buildings: A Determination Method to Promote Flexible and Sustainable Construction." In Proceedings UIA 2014 Architecture Otherwhere., edited by Osman, A., Bruyns, G., and Aigbavboa, C. Durban, UIA 2014 Durban: 1054.

\footnotetext{
1 Taekema, H., Ymere; Van Denzen, O., Eigen Haard; Moll, W., Van Dam, M., Syntrus Achmea; Sevenheck, F., Mitros; Dekkers, E.J., Roomer, R., Bouwinvest.
} 
[2] Remøy, H. 2013. A Sustainable Real Estate Strategy, Design for Change, Urban Adaptation Strategies. Delft: Delft University of Technology.

[3] Ruiterkamp, J. 2015. The Possibility to Implement Flexibility Measures in Housing with a Successful Business Case (De Mogelijkheid om met een Sluitende Business case Flexibiliteitsmaatregelen te Implementeren in Woningen). Delft: TU Delft: 128. (in Dutch)

[4] De Jonge, H. L., Arkestein, M. H., Den Heijer, A. C., Vande Putte, H. J. M., De Vries, J. C., and Van der Zwart, J. 2009. Corporate Real Estate Management, Designing an Accommodation Strategy. Delft: Delft University of Technology.

[5] Van Belzen, T. 2014. "Construction of Informal Care Houses License Free." Bouw Mantelzorgwoningen Vergunningvrij. Cobouw (6 June 2014).

[6] Boterman, B. 2014. Interview with Bram Boterman. Housing developer at Heijmans Real Estate.

[7] Roders, M. J. 2003. "IFD Construction in Japan, America and Europa." In Proceedings ISARC2003. Eindhoven.

[8] Shing, K. 2001. Demand-Driven Building: A Research of Flexibility in IFD Housing (Vraaggestuurd Bouwen, een Onderzoek naar Flexibiliteit in IFD Woningen). Delft University of Technology. (in Dutch)

[9] Geraedts, R. 2011. "Succes and Failure in Flexible Building." Open House International 36: 54-63.

[10] Scanlon, K., and Kochan, B. 2011. Towards a Sustainable Private Rental Sector. London: The London school of
Economics and Political Science.

[11] Feijten, P., and Visser, P. 2005. "Domestic Migration: Moving Motifs and Moving Distance (Binnenlandse Migratie: Verhuismotieven en Verhuisafstand)." Bevolkingstrends 56: 52-59. (in Dutch)

[12] Gambles, I. 2009. Making the Business Case. Cornwall: MPG Books Ltd.

[13] Van Putten, B. J. 2012. Supporting Reuse in Business Case Development. Wiesbaden: Springer Gabler.

[14] Heijmans. 2014. Flexible Row-Dwelling Concept of Real Estate Developer Heijmans (so-called Huismerk Dwelling). http://heijmans.nl/nl/nieuws/huismerk-huizenleeswand-waalwijk-verkocht.

[15] Meesters, J. 2006. The Meaning of Activities in the Dwelling and Residential Environment. Delft: TU Delft.

[16] Hermans, M., Geraedts, R., Van Rijn, E., Remoy, H. (2014). Assessment Method Adaptive Capacity of Buildings to Stimulate Flexible Building (Bepalingsmethode Adaptief Vermogen van Gebouwen ter Bevordering van Flexibel Bouwen). Leidschendam: Brink Groep. (in Dutch)

[17] Hulhoven, B. 2014. Costs Calculation for the Case. BBN Advisors.

[18] Smits, T. 2014. Interview with Coordinator Sustainability Heijmans.

[19] GPR. 2016. Green Performance of Real Estate Score (GPR-Gebouw) 2016. Accessed February 22, 2016. http://gprsoftware.nl/english. 